Volume 8, No.5, September - October 2019

International Journal of Advanced Trends in Computer Science and Engineering

Available Online at http://www.warse.org/IJATCSE/static/pdf/file/ijatcse79852019.pdf

https://doi.org/10.30534/ijatcse/2019/79852019

\title{
Promethee Based Distributed Coverage and Connectivity Preserving Scheduling Algorithm for MWSN
}

\author{
${ }^{\# 1}$ Jitendra Singh Verma, ${ }^{\# 2}$ Sanjeev Sharma \\ ${ }^{\# 1}$ School of Information Technology, RGPV, Bhopal, India, jitendrasingh.v@gmail.com \\ ${ }^{\# 2}$ School of Information Technology, RGPV, Bhopal, India, sanjeev@ rgtu.net
}

\begin{abstract}
In this paper we can propose a Promethee Based Distributed Coverage and Connectivity Preserving Scheduling Algorithm for Mobile Wireless Sensor Network (PDCCPSA) with the objective to increase the network lifetime with the capability to persistently provide coverage and connectivity of the whole observed area using turning off some nodes or schedule sensor to work alternatively based on multi criteria. In this paper, we look at Preference Ranking Organization Method for Enrichment Evaluations (PROMETHEE) and coverage aware cost matrices for optimal assignment of cluster head, active and sleep nodes using multi criteria. The outcomes of simulation shows that PDCCPSA efficiently grow the network's life, persistently provide the coverage constantly and decrease the number of hops between member nodes and sink.
\end{abstract}

Key words: Promethee, Coverage, preservation, Node Scheduling, Energy Consumption.

\section{INTRODUCTION}

Mobile sensor is very useful in various applications such as surveillance system, tracking system, intelligent traffic system, smart cities, agriculture, disaster management, industries and many more application of IoT (Internet of Things) [1,2]. The wireless sensor nodes are usually equipped with limited energy source and densely deployed make it quite hard to recharge batteries [3]. Therefore energy consumption, lifetime of network, coverage, connectivity, optimum choosing of cluster head, load allocation are the important research issues in the arena of WSN $[4,5]$.

To resolve the problem of balanced energy consumption with coverage aware node scheduling algorithm has presented in [6] use PCH (Primary Cluster Head) and SCHs (Secondary Cluster Head) in each cluster for support the $\mathrm{PCH}$ in case $\mathrm{PCH}$ goes to die. In [7], authors proposed an inner cluster scheduling algorithm, inner cluster algorithm only select $\mathrm{k}$ sensors with maximum remaining energy which are adjacent to static sensors for decreases the data delay and energy consumption. In MADSEC [8],
Energy efficient clusters formed by distributed clustering algorithm which is run by mobile nodes. In EFTCP [9], member nodes of cluster have the time slot which is assign by the cluster head for sending the data as per amount of information. In [10], we have introduced PDMECCA for preserve the coverage and energy for mobile sensor nodes using promethee method. Most of the scheduling algorithm proposed in the past for preserve the coverage and connectivity for static nodes. In [11] authors consider the coverage and energy preservation problem simultaneously for static nodes. Soro and Heinzelman [11] select the cluster head, active nodes, sleep nodes and router using coverage aware matrices. In [12], authors proposed a scheduling method for static nodes and divides the nodes into clusters and group cluster members into sponsor set depend on neighbour data for uniformly distribute the workload between nodes. In the past energy, coverage and connectivity preservation protocols and scheduling for mobile sensor network have not been combined in a comprehensible fashion. Therefore this paper propose a PDCCPSA with extra emphasis on the optimal route, active node selection, coverage, connectivity and cluster head selection.

\section{NETWORK MODEL}

Proposed algorithm PDCCPSA has number of mobile sensors nodes and single stationary base station. Sensor nodes travel casually in any direction with dynamic speed using simple first order radio model within the network boundaries, all nodes are homogenous and we assume a perfect Medium Access Control layer conditions.

\section{OVERVIEW OF COVERAGE AWARE COST METRICS}

This paper incorporates the weighted sum coverage cost [11] and coverage redundancy cost [11] which is known as coverage cost for preserve the coverage.

Sensors have little remaining energy and high coverage cost should be: 
- Prohibited to working as a head of cluster.

- Prohibited to traveling one location to another.

- Prohibited to contributing in data transmitting.

\section{Coverage cost $=$ Weighted sum coverage cost $*$ Coverage redundancy cost}

The weighted-sum coverage cost is formulate as

$\mathrm{C}_{\mathrm{ws}}(\mathrm{i})=\int_{C(i)} \frac{d x d y}{\operatorname{Etotal}(x, y)}=\int_{C(i)} \frac{d x d y}{\sum_{j:(x, y) \in C(j)} E(j)}$

This cost metric calculate the weighted average of the total energies of all points which are covered by node i.where $E_{\text {total }}(x, y)$ is the total available energy for observing that place.

The Coverage redundancy cost is formulate as

Coverage redundancy cost $=\int_{C(i)} \frac{d x d y}{\operatorname{Ototal}(x, y)}$

In the equation, Ototal $(\mathrm{x}, \mathrm{y})$ is a total coverage that offers the various nodes which cover every point $(\mathrm{x}, \mathrm{y})$ of the region.

Where $\mathrm{O}_{\text {total }}=\sum_{i:(x, y) \in C(i)} 1$

\section{OVERVIEW OF PROMETHEE METHOD}

It is a decision creating or outranking method work on multi criteria. It is work on extensions of the notion of criterion. This extension is based on the preference function $(\mathrm{P})$ giving the preference to an action (alternative) a with regard to b. For two particular actions (a) and (b), the preference function of (a) with regard to (b) can be defined as [13]:

When maximize the criteria

$$
P(a, b)=\left\{\begin{array}{r}
0, \text { if } f(a) \leq f(b) \\
P[f(a), f(b)], \text { if } f(a)>f(b)
\end{array}\right.
$$

When minimize the criteria:

$$
\begin{aligned}
& P(a, b)=\left\{\begin{array}{r}
0, \text { if } f(a) \geq f(b) \\
P[f(a), f(b)], \text { if } f(a)<f(b)
\end{array}\right. \\
& \mathrm{P}[\mathrm{f}(\mathrm{a}), \mathrm{f}(\mathrm{b})]=\mathrm{P}[\mathrm{f}(\mathrm{a})-\mathrm{f}(\mathrm{b})]
\end{aligned}
$$

Value of action $a$ and $b$ are $f(a)$ and $f(b)$ respectively in equation 3.

PROMETHEE can be categorized into two methods are PROMETHEE I and PROMETHEE II for resolving the decision making problem:

5.1 PROMETHEE I: Ranking the action by a partial pre order using the following equations:

Preference Index: $a, b \varepsilon \mathrm{K}$ are pair of action, Preference index for a with regard to $\mathrm{b}$ over all the criteria.

$$
\begin{aligned}
& \pi(\mathrm{a}, \mathrm{b})=\frac{1}{K} \sum_{h=1}^{k} P_{h}(\mathrm{a}, \mathrm{b}) \\
& \Phi^{+}(a)=\sum_{x \in k} \pi(a, x) \\
& \Phi^{-}(a)=\sum_{x \in k} \pi(x, a)
\end{aligned}
$$

In equation $8, \mathrm{P}$ is a function of preference and $\mathrm{k}$ is number of possible actions.

In equation $9, \Phi^{+}(a)$ is an Outgoing flow and in equation $10, \Phi^{-}(a)$ is an incoming flow.

5.2 PROMETHEE II: Ranking the actions by a total preorder using:

$$
\Phi(a)=\Phi^{+}(a)-\Phi^{-}(a)
$$

In equation $11, \Phi(a)$ is a net flow.

\section{PRELIMINARIES}

The symbolisations, description and its values which are used in proposed algorithm PDCCPSA are listed in Table 1.

Table 1: Symbolization, Description and Values

\begin{tabular}{|l|l|l|l|l|l|}
\hline Symbolization & Description & Value & Symbolisation & Description & Value \\
\hline $\mathrm{N}$ & $\begin{array}{l}\text { Number of } \\
\text { nodes }\end{array}$ & $\begin{array}{l}100,150, \\
200,250, \\
300,350\end{array}$ & $\mathrm{E}_{0}$ & $\begin{array}{l}\text { Initial energy in } \\
\text { joule }\end{array}$ & $0.5 \mathrm{~J}$ \\
\hline Network Region & $\begin{array}{l}\text { Total region of } \\
\text { network }\end{array}$ & $100 \mathrm{X} 100$ & $\mathrm{E}_{\mathrm{rx}}$ & $\begin{array}{l}\text { Receiving energy } \\
\text { in joule }\end{array}$ & Evaluated \\
\hline $\mathrm{BS}$ & Base Station & $\begin{array}{l}{[0,0]} \\
\text { coordinate }\end{array}$ & $\mathrm{E}_{\mathrm{tx}}$ & $\begin{array}{l}\text { Transmission } \\
\text { energy in joule }\end{array}$ & Evaluated \\
\hline $\mathrm{E}_{\mathrm{res}}$ & $\begin{array}{l}\text { Remaining } \\
\text { energy in joule }\end{array}$ & Evaluated & $\mathrm{E}_{\mathrm{computation}}$ & $\begin{array}{l}\text { Computation } \\
\text { Energy }\end{array}$ & $8 \mathrm{~nJ}$ \\
\hline FREQUENCY $_{\mathrm{CH}}$ & Number of times & Evaluated & $\mathrm{E}_{\mathrm{DA}}$ & Data & $4 \mathrm{~nJ}$ \\
\hline
\end{tabular}




\begin{tabular}{|c|c|c|c|c|c|}
\hline & $\begin{array}{l}\text { (frequency) node } \\
\text { became the } \mathrm{CH}\end{array}$ & & & $\begin{array}{l}\text { Accumulation } \\
\text { Energy }\end{array}$ & \\
\hline FREQUENCY ${ }_{\text {ACTIVE }}$ & $\begin{array}{l}\text { Number of times } \\
\text { (frequency) node } \\
\text { became the } \\
\text { Active. }\end{array}$ & Evaluated & Packet Size & Size of Packet & 320 bit \\
\hline $\mathrm{S}_{\text {range }}$ & $\begin{array}{l}\text { Highest range of } \\
\text { sensing }\end{array}$ & $\begin{array}{l}15 \mathrm{~m} \\
\text { (Meter) }\end{array}$ & $\begin{array}{l}\text { Broadcast } \\
\text { Packet Size }\end{array}$ & $\begin{array}{l}\text { Size of Broadcast } \\
\text { Packet }\end{array}$ & 40 bit \\
\hline $\mathrm{T}_{\text {range }}$ & $\begin{array}{l}\text { Highest range of } \\
\text { transmission }\end{array}$ & $\begin{array}{l}40 \mathrm{~m} \\
\text { (Meter) }\end{array}$ & $\begin{array}{l}\text { Transmitted } \\
\text { Data Size }\end{array}$ & $\begin{array}{l}\text { Data's size to be } \\
\text { communicated }\end{array}$ & $\begin{array}{l}\text { Packet Size * } \\
\text { Number of } \\
\text { Packet }\end{array}$ \\
\hline $\mathrm{E}_{\text {elec }}$ & $\begin{array}{l}\text { Energy } \\
\text { consumption of } \\
\text { electronic circuit } \\
\text { in transmission } \\
\text { and reception in } \\
\text { joule }\end{array}$ & $50 \mathrm{~nJ} / \mathrm{bit} / \mathrm{m}$ & & & \\
\hline
\end{tabular}

6 CLUSTERING ARCHITECTURE AND DATA DISSEMINATION OF PROPOSED ALGORITHM

Proposed algorithm can be work into round and further each round categorized into architecture designing phase, Active and Sleep nodes selection phase and Data dissemination phase. In proposed algorithm, assume $\mathrm{N}$ total sensor nodes $\left(\mathrm{S}_{1}, \mathrm{~S}_{2}, \mathrm{~S}_{3}\right.$, --,$- \mathrm{S}_{\mathrm{N}}$ ) are distributed randomly over a rectangular observed area.

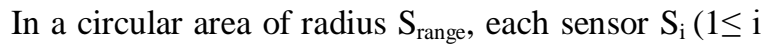
$\leq \mathrm{N})$ performs sensing.

\subsection{Clustering architecture designing phase}

Proposed algorithm divides the nodes into four groups are Member node (MN), False cluster head $(\mathrm{FCH})$, Cluster head $(\mathrm{CH})$, Sink. Clustering architecture of proposed algorithm PDCCPSA shows in Figure 1.

The purpose behind categorizing the sensors are:

- Uniform spreading of workload or duty (computation, cluster head selection, data accumulation, data transmission) among mobile sensor nodes.

- Avoiding lengthy distance transmission.

- Reduction of energy consumption.

- Removing the information redundancy.

Clustering architecture designing phase can be categorized into Cluster Formation and Cluster Heads selection phase.

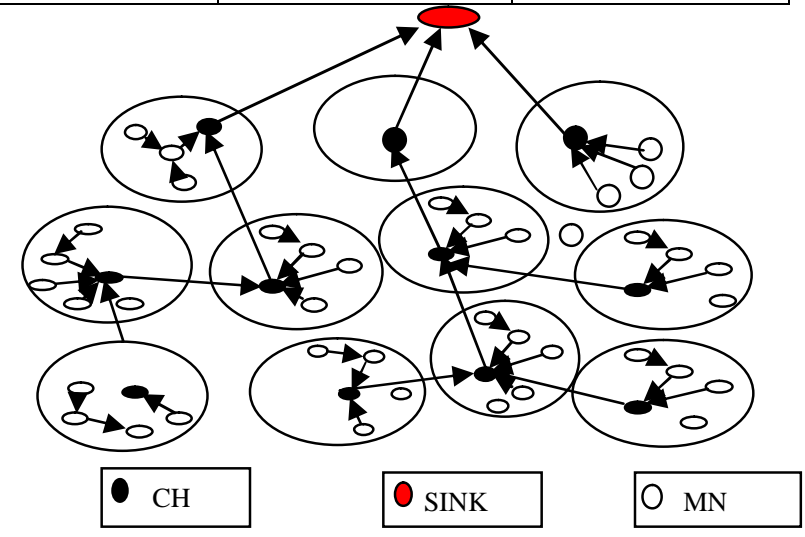

Figure 1: Clustering Architecture of PDCCPSA

The basic terms and its formal definition which are related to the cluster formation and head selection phase are listed below:

Definition 1: $\mathrm{SN}[1: \mathrm{N}]$ is a single dimensional array of collection of alive sensor nodes. $\mathrm{N}$ is total number of nodes.

$$
\mathrm{SN}[1: \mathrm{N}]=\left\{\mathrm{E}_{\mathrm{res}}(\mathrm{SN})>0\right\} \text {; }
$$

Definition 2: $\mathrm{FCH}[1: \mathrm{M}]$ is a single dimer array of collection of false cluster head. $\mathrm{M}$ is total number of $\mathrm{FCH}$.

Definition 3: MN_FCH [ ] is a multi dimensional array of collection of member nodes of particular FCH. So it is written as MN_FCH $(\mathrm{FCH}(\mathrm{t}),:)$. Where $(1 \leq \mathrm{t} \leq \mathrm{M}), \mathrm{t}$ is total number of $\mathrm{FCH}$.

Definition 4: N_MN_FCH [ ] is a single dimensional array. It shows the number of member nodes of particular FCH. 
Definition 5: $\operatorname{dist}()$ is a function of distance. It calculates the distance between two nodes.

Definition 6: $\mathrm{MN} \_\mathrm{CH}[\mathrm{]}$ is a multi dimensional array of collection of member nodes of particular $\mathrm{CH}$. So it is written as MN_CH (CH (i), :). In which, $\mathrm{t}$ is total number of $\mathrm{FCH}$. Where $(1 \leq \mathrm{i} \leq \mathrm{H}), \mathrm{H}$ is a total number of cluster head.

Definition 7: NN[ ] is a single dimensional array of size $\mathrm{P} . \mathrm{P}$ is total number of normal nodes.

Definition 8: N_MN_CH [ ] is a single dimensional array. It represent the number of member nodes of particular $\mathrm{CH}$.

\subsubsection{Cluster Formation}

Each node produces the arbitrary number between 0 and 1. If arbitrary number is higher than threshold number (0.3) then it will work as a false cluster head otherwise persist as a normal node. False cluster head is liable for making the cluster or work as a cluster's representative. False Cluster Head broadcast its remaining energy, position and status within the $2 * S_{\text {range }}$ range to its neighbor nodes. Based on distance normal node join cluster. Distance among each node of cluster including false cluster head should be smaller than or equal to $2 * S_{\text {range. }}$ Therefore cluster maintain the utmost range is $S_{\text {range. If any node }}$ is not become the member of any cluster then it will become the cluster head. Algorithm 1 Cluster Formation given below describes the process of cluster formation.

\section{Algorithm Cluster Formation (N)}

// $\mathrm{RN}$ is random number. $\mathrm{U}$ is used for union operation.

1. \{

2. $\mathrm{FCH}=[] ; \mathrm{NN}=[] ; \mathrm{MN} \_\mathrm{FCH}(\mathrm{FCH}(\mathrm{t}),:)=[]$;

3. for $\mathrm{i}=1$ to $\mathrm{N}$

4. \{

5. if $\mathrm{RN}$ (i) $<=$ Threshold_Value

6. $\mathrm{FCH}=\mathrm{FCH} \cup \mathrm{i}$

7. else

8. $\quad$ NormalNode $=$ NormalNode $\cup \mathrm{i}$;

9. $\}$

10. Clear i;

11. for $\mathrm{j}=1$ to $\mathrm{P}$

12. \{

13. $\quad$ Sdist $=\operatorname{sort}(\operatorname{dis}(\mathrm{NN}(\mathrm{j}), \mathrm{FCH}))$;

// Sdist holds the value of distance between normal node $(\mathrm{j})$ and $\mathrm{FCH}$ in ascending order.
14. for $\mathrm{k}=1$ to $\mathrm{Q}$
15. \{
16. for $\mathrm{t}=1$ to $\mathrm{M}$
17. \{

18. if $\operatorname{dist}(\mathrm{NN}(\mathrm{j}), \mathrm{FCH}(\mathrm{t}))==\operatorname{Sdist}(\mathrm{k}) \& \&$ $\operatorname{dist}(\mathrm{NN}(\mathrm{j}), \mathrm{FCH}(\mathrm{t})) \leq 2 * \mathrm{~S}_{\text {range }}$;

19. if N_MN_FCH(FCH(t)) $>0$

20. if dist $\left(\mathrm{NN}(\mathrm{j}), \mathrm{MN} \_\mathrm{FCH}(\mathrm{FCH}(\mathrm{t}))\right) \leq 2 * \mathrm{~S}_{\text {range }}$

21. MN_FCH $(F C H(t)$, end +1$)=\mathrm{NN}(\mathrm{j})$;

// MN_FCH (FCH (t)) is member nodes of FCH (t).

22. else

23. break;

24. else

25. MN_FCH $(\mathrm{FCH}(\mathrm{t})$, end +1$)=\mathrm{NN}(\mathrm{j})$;

26. $\}$

27. $\}$

28. $\}$

29. if

$\mathrm{MN} \_\mathrm{FCH}(\mathrm{FCH}(1),:) \cup \mathrm{MN} F \mathrm{FCH}(\mathrm{FCH}(2),:) \cup$ $---\cup \mathrm{MN} \_\mathrm{FCH}(\mathrm{M},:) \neq \mathrm{NN}$;

30. $R=\mathrm{NN}-(\mathrm{MN}$ FCH $(\mathrm{FCH}(1),:) \cup$ $\mathrm{MN}$ FCH $(\mathrm{FCH}(2),:) \cup---\cup \mathrm{MN}$ FCH $(\mathrm{M}$, : ) )

// '-' is used for set difference operation.

31. $\mathrm{FCH}($ end +1 : length $(\mathrm{R}))=\mathrm{R}$;

32. $\}$

\section{Algo.1 Cluster Formation}

\subsubsection{Cluster Heads Selection}

False cluster head select the $\mathrm{CH}$ through PROMETHEE work on multi criteria (remaining energy, average distance to cluster member node, distance to sink node and CH's frequency) in each cluster and broadcast position of $\mathrm{CH}$ to all member node of cluster. This phase increase the remaining energy criteria and decrease the average distance to cluster member node, distance to base station, FREQUENCY $_{\mathrm{CH}}$ and coverage cost criteria. So FCH chooses the optimum $\mathrm{CH}$ that has high remaining energy, least average distance to cluster member node, least distance to base station, least FREQUENCY $\mathrm{CH}_{\mathrm{CH}}$, and least cost of coverage. $\mathrm{CH}$ is liable for accumulation of information that is come from member nodes and transmitting the accumulated data to the base station through multihop transmission.

\subsection{Active and Sleep node selection phase}

In Active and Sleep nodes selection phase, cluster head selects sleep nodes using PROMETHEE work on multi criteria (remaining energy, frequency of Active nodes, distance with cluster head and coverage cost) in each cluster for preserve the energy and increase the network lifetime.This phase minimize the remaining energy criteria, maximize the distance to cluster head, maximize FREQUENCY ${ }_{\text {ACTIVE }}$ and minimize coverage cost criteria. So $\mathrm{CH}$ select node which has less $\mathrm{E}_{\text {res}}$, high FREQUENCY ${ }_{\text {ACtIVE}}$, high distance with cluster head and minimum coverage 
cost as a sleep node. For preserve the connectivity and coverage, Active and Sleep node selection phase apply only on cluster which has total number of nodes include $\mathrm{CH}$ greater than 3 and only one node become the sleep. Remaining nodes are known as active nodes. Active nodes are used for performing sensing and data dissemination task for current round. $\mathrm{CH}$ broadcast list and location of Active and Sleep nodes to all member nodes of cluster. The selected active nodes provide full coverage of monitored area. Algorithm Active_Sleep_Node_Selection given below describes the process of Active and Sleep nodes selection using PROMETHEE method.

Algorithm Active_Sleep_Node_Selection (N, E dist, FREQUENCY ${ }_{\text {ACTIVE }}$, Coverage cost, MN_CH, $\mathrm{CH}, \mathrm{N} \_\mathrm{MN} \_\mathrm{CH}$ )

// $\mathrm{U}$ is used for union operation. $\mathrm{N}_{\mathrm{S}}$ and $\mathrm{N}_{\mathrm{A}}$ are the set //of sleep nodes and active nodes respectively.

1. \{

2. $\mathrm{N}_{\mathrm{S}}=[] ; \quad \mathrm{N}_{\mathrm{A}}=[]$;

3. for $\mathrm{i}=1$ to $\mathrm{CH}$

4. \{

5. $\mathrm{N}_{\mathrm{MN}}=\mathrm{N} \_\mathrm{MN} \_\mathrm{CH}(\mathrm{CH}(\mathrm{i}))$;

6. if $\mathrm{N}_{\mathrm{MN}}>3$

7. $\pi=\operatorname{zeros}\left(\mathrm{N}_{\mathrm{MN}}, \mathrm{N}_{\mathrm{MN}}\right)$;

8. for $\mathrm{j}=1$ to $\mathrm{N}_{\mathrm{MN}}$

9. \{

10. for $\mathrm{k}=1$ to $\mathrm{N}_{\mathrm{MN}}$

11. \{

12. if $\mathrm{j} \sim=\mathrm{k}$

13. \{

14. if $\mathrm{E}_{\mathrm{res}}\left(\mathrm{MN} \_\mathrm{CH}(\mathrm{CH}(\mathrm{i}), \mathrm{j})\right)<\mathrm{E}_{\text {res }}\left(\mathrm{MN} \_\mathrm{CH}(\mathrm{CH}(\mathrm{i})\right.$, $\mathrm{k})$ )

15. if $\left(\mathrm{E}_{\mathrm{res}}\left(\mathrm{MN} \_\mathrm{CH}(\mathrm{CH}(\mathrm{i}), \mathrm{j})\right)-\mathrm{E}_{\text {res }}\left(\mathrm{MN} \_\mathrm{CH}\right.\right.$ $(\mathrm{CH}(\mathrm{i}), \mathrm{k})))>0$

16. $\pi(\mathrm{j}, \mathrm{k})=\pi(\mathrm{j}, \mathrm{k})+1$;

17. else

18. $\pi(\mathrm{j}, \mathrm{k})=\pi(\mathrm{j}, \mathrm{k})+0$;

19. else

20. $\pi(\mathrm{j}, \mathrm{k})=\pi(\mathrm{j}, \mathrm{k})+0$;

// In similar way as step 11-20, find out the value of $\pi$ for remaining criteria.

19. $\pi(\mathrm{j}, \mathrm{k})=\pi(\mathrm{j}, \mathrm{k}) \cdot /\left(\mathrm{N}_{\mathrm{MN}}\right)$;

21. $\}$

22. $\}$

23. $\}$

24. $\phi^{+}=(\text {sum_row }(\pi))^{\prime}$;

25. $\phi^{-}=$sum_colum $(\pi)$;

24. Net_flow $=\phi^{+}-\phi^{-}$;

$25 . \mathrm{N}_{\mathrm{S} \_ \text {position }}=$ find $\left(\mathrm{Net} \_\right.$flow $==\max ($ Net_flow $\left.)\right)$;

26. $N_{S}=\mathrm{MN} \_\mathrm{CH}\left(\mathrm{CH}(\mathrm{i}), \overline{\mathrm{N}}_{\mathrm{S} \_} \operatorname{position}(1)\right) \cup \mathrm{Ns}$;

27. $\}$

26. $N_{A}=S N-N_{S}$;

27. $\}$

\section{Algo.2 Active and Sleep Node Selection}

According to the algorithm (2) active and sleep node selection can be illustrated through following example. Figure 2 shows the cluster which has five nodes A, B, C, D, E and node B is a cluster head.

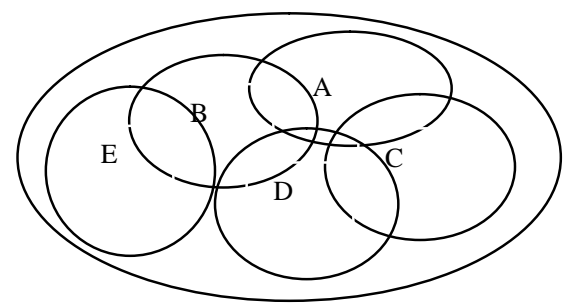

Figure 2: Illustrated Example of Active and Sleep Node Selection

Table 2 shows the distance between nodes. Remaining energy of A, B, C, D and E nodes are 0.3, $0.4, \quad 0.2, \quad 0.4$ and 0.25 respectively. FREQUENCY $_{\text {ACTIVE }}$ of A, B, C, D and E nodes are $1,2,0,0$ and 1 respectively. Total available energy (Etotal) and total available nodes (Ototal) for monitor the area $\mathrm{A}, \mathrm{B}, \mathrm{C}, \mathrm{D}, \mathrm{E}, \mathrm{EB}, \mathrm{BD}, \mathrm{AB}, \mathrm{AC}, \mathrm{CD}, \mathrm{AD}$, $\mathrm{ABD}, \mathrm{ACD}$ are given in following equations.

$$
\begin{aligned}
& \operatorname{Etotal}(\mathrm{x}, \mathrm{y})=\left\{\begin{array}{c}
0.3,(x, y) \in A \\
0.4,(x, y) \in B \\
0.2,(x, y) \in C \\
0.4,(x, y) \in D \\
0.25,(x, y) \in E \\
0.65,(x, y) \in E B \\
0.8,(x, y) \in B D \\
0.7,(x, y) \in A B \\
0.5,(x, y) \in A C \\
0.6,(x, y) \in C D \\
0.7,(x, y) \in A D \\
1.1,(x, y) \in A B D \\
0.9,(x, y) \in A C D
\end{array}\right. \\
& \operatorname{Ototal}(\mathrm{x}, \mathrm{y})=\left\{\begin{array}{c}
1,(x, y) \in A \\
1,(x, y) \in B \\
1,(x, y) \in C \\
1,(x, y) \in D \\
1,(x, y) \in E \\
2,(x, y) \in E B \\
2,(x, y) \in B D \\
2,(x, y) \in A B \\
2,(x, y) \in A C \\
2,(x, y) \in C D \\
2,(x, y) \in A D \\
3,(x, y) \in A B D \\
3,(x, y) \in A C D
\end{array}\right.
\end{aligned}
$$

Weighted sum coverage cost:

$\mathrm{C}_{\mathrm{ws}}(\mathrm{A})=1 / 0.3+1 / 0.7+1 / 0.5+1 / 0.7+1 / 1.1+1 / 0.9=$ 10.21

$\mathrm{C}_{\mathrm{ws}}(\mathrm{B})=1 / 0.4+1 / 0.65+1 / 0.8+1 / 0.7+1 / 1.1=7.62$

$\mathrm{C}_{\mathrm{ws}}(\mathrm{C})=1 / 0.2+1 / 0.5+1 / 0.6+1 / 0.9=9.77$ 
$\mathrm{C}_{\mathrm{ws}}(\mathrm{D})=1 / 0.4+1 / 0.8+1 / 0.6+1 / 0.7+1 / 1.1+1 / 0.9=$ 8.86

$\mathrm{C}_{\mathrm{ws}}(\mathrm{E})=1 / 0.25+1 / 0.65=5.53$

Coverage Redundancy Cost:

$\mathrm{C}_{\mathrm{crc}}(\mathrm{A})=1 / 1+1 / 2+1 / 2+1 / 2+1 / 3+1 / 3=3.16$

$\mathrm{C}_{\mathrm{crc}}(\mathrm{B})=1 / 1+1 / 2+1 / 2+1 / 2+1 / 3=2.83$

$\mathrm{C}_{\mathrm{crc}}(\mathrm{C})=1 / 1+1 / 2+1 / 2+1 / 3=2.33$

$\mathrm{C}_{\mathrm{crc}}(\mathrm{D})=1 / 1+1 / 2+1 / 2+1 / 2+1 / 3+1 / 3=3.16$

$\mathrm{C}_{\mathrm{crc}}(\mathrm{E})=1 / 1+1 / 2=1.5$

\section{Coverage Cost:}

$\operatorname{Ccc}(\mathrm{A})=\mathrm{C}_{\mathrm{ws}}(\mathrm{A}) * \mathrm{C}_{\mathrm{crc}}(\mathrm{A})=32.26$

$\operatorname{Ccc}(\mathrm{B})=\mathrm{C}_{\mathrm{ws}}(\mathrm{B}) * \mathrm{C}_{\mathrm{crc}}(\mathrm{B})=21.56$

$\mathrm{Ccc}(\mathrm{C})=\mathrm{C}_{\mathrm{ws}}(\mathrm{C}) * \mathrm{C}_{\mathrm{crc}}(\mathrm{C})=22.76$

$\mathrm{Ccc}(\mathrm{D})=\mathrm{C}_{\mathrm{ws}}(\mathrm{D}) * \mathrm{C}_{\mathrm{crc}}(\mathrm{D})=27.99$

$\operatorname{Ccc}(\mathrm{E})=\mathrm{C}_{\mathrm{ws}}(\mathrm{E}) * \mathrm{C}_{\mathrm{crc}}(\mathrm{E})=8.29$

Table 2: Distances (Meter)

\begin{tabular}{|l|l|l|l|l|l|}
\hline Distance & A & B & C & D & E \\
\hline A & 0 & 2 & 3 & 6 & 9 \\
\hline B & 2 & 0 & 4 & 1 & 3 \\
\hline C & 3 & 4 & 0 & 3 & 8 \\
\hline D & 6 & 1 & 3 & 0 & 4 \\
\hline E & 9 & 3 & 8 & 4 & 0 \\
\hline
\end{tabular}

Using equation 5 to 11 in the proper mode as per the criteria can be minimized or maximized get for $\pi\left(a_{i}\right.$ $\left.a_{j}\right), i, j=A, B, C, D$ and $E$, the values found in Table 3 shows the value of preference index, incoming flow, outgoing flow and Net_flow. Based on Net_flow value, PROMETHEE method gives the first rank to node $\mathrm{D}$ and second rank to $\mathrm{B}$. Therefore Node D or Node B select as a sleep node and remaining nodes will become as active nodes.

Table 3: Value of $\pi\left(a_{i}, a_{j}\right), \phi^{+}, \phi^{-}$and Net_flow

\begin{tabular}{|l|l|l|l|l|l|l|}
\hline & $\mathrm{A}$ & $\mathrm{B}$ & $\mathrm{C}$ & $\mathrm{D}$ & $\mathrm{E}$ & $\Phi^{+}$ \\
\hline $\mathrm{A}$ & 0 & 0 & 0.2 & 0 & 0.2 & 0.4 \\
\hline $\mathrm{B}$ & 0.2 & 0 & 0.2 & 0 & 0.2 & 0.6 \\
\hline $\mathrm{C}$ & 0 & 0 & 0 & 0 & 0 & 0 \\
\hline $\mathrm{D}$ & 0.2 & 0 & 0.2 & 0 & 0.2 & 0.6 \\
\hline $\mathrm{E}$ & 0 & 0 & 0.2 & 0 & 0 & 0.2 \\
\hline$\Phi^{-}$ & 0.4 & 0 & 0.8 & 0 & 0.6 & \\
\hline Net_flow & 0 & 0.6 & -0.8 & 0.6 & -0.4 & \\
\hline
\end{tabular}

\subsection{Data dissemination phase}

There are two parts of Data dissemination phase

\subsubsection{Intra Cluster Communication}

TDMA slot distributes by $\mathrm{CH}$ to the member node. Member node send sensed information to $\mathrm{CH}$ through path_cost (eq. 14) matrix and Coverage_preserving_path_cost (eq. 13) matrix using number of hop transmission. Node with least Coverage_preserving_path_cost and fulfil path_cost matrix nominated as a succeeding relay node.

6.3.2 Inter Cluster Communication: $\mathrm{CH}$ nodes send the accumulated information to sink node using multihop transmission. $\mathrm{CH}$ with least Coverage_preserving_path_cost (eq. 13) matrix and using either optimal path (eq. 15) or feasible path (eq. 16) selection matrix nominated as a succeeding relay $\mathrm{CH}$.

Coverage_preserving_path_cost $(\mathrm{i}, \mathrm{j})=$ coverage cost $* \operatorname{Etx}(i, j)+$ coverage cost . $\operatorname{Erx}(i, j)$

This Coverage_preserving_path_cost confirms that nodes are essential to coverage are least expected to contribute in transmission as a hop node.

Path_Cost $(\mathrm{i}, \mathrm{j})=\mathrm{E}_{\text {res }}(\mathrm{j})>$

$\min \left(E_{\text {res }}(\mathrm{cmn})\right) \& \&$ dis $(i, j) \leq S_{\text {range }}$ or $2 *$

$S_{\text {range }}$

$\operatorname{Path}_{\text {Cost }}(\mathrm{i}, \mathrm{j})=E_{\text {res }}(\mathrm{j})>$

$\min \left(\mathrm{E}_{\mathrm{res}}\left(C_{\text {set }}\right)\right) \& \&$ dist $(i, j) \leq S_{\text {range }}$ or $2 *$

$S_{\text {range }}$ or $T_{\text {range }}$

Path_Cost $(\mathrm{i}, \mathrm{j})=\mathrm{E}_{\mathrm{res}}(\mathrm{j})>$ $\min \left(\mathrm{E}_{\mathrm{res}}(\mathrm{CH}\right.$ set $\left.)\right) \| \operatorname{dist}(i, j) \leq T_{\text {range }}$

In equation 13, 14, 15 and 16, i consider as a (16) consider as a succeeding relay node, $\mathrm{cmn}$ is cusum member node and CH_set is CH's collection. These path_cost confirms nodes that have less energy and high distance with source sensor node are least expected to contribute in transmission as a hop node. Nodes which have a low coverage redundancy, it cannot move from one position to another position to preserve the coverage.

\section{RESULT AND ANALYSIS}

Proposed algorithm PDCCPSA is simulate and evaluate in matlab R2012b. Table 1 shows the parameter which are used in simulation and evaluation. In figure 3, utmost of the nodes shows same remaining energy level approximate performance of 0.3 joule after 1000 round. So we can say that load uniformly distribute in all nodes. According to figure 4, all nodes alive till 3380 round, first node die on 2548 round and last node dies on 3380 round for 100 nodes. All nodes alive till 3295 
round, first node die on 2379 round and last node dies on 3295 round for 350 nodes. According to figure 5, proposed algorithm PDCCPSA offers the almost complete coverage (100\%) till 2689 and 2753 rounds for 100 and 350 nodes respectively after that coverage slowly goes to down. According to figure 6, proposed algorithm PDCCPSA continuously provide the $100 \%$ coverage till $3.7319 \mathrm{e}^{+05}, 3.3737 \mathrm{e}^{+05}$, $3.9068 \mathrm{e}^{+05}, 2.6722 \mathrm{e}^{+05}, 3.0595 \mathrm{e}^{+05}$ and $2.1549 \mathrm{e}^{+05}$ seconds for 100, 150, 200, 250, 300 and 350 nodes respectively after that coverage slowly goes to down. Proposed algorithm increase the lifetime of network till 2078, 3593, 3413, 3614, 3384 and 3294 rounds for $100,150,200,250,300$ and 350 nodes respectively. Energy, coverage preservation and scheduling for mWSN have not been combined in a comprehensible fashion. Therefore first, this paper compare the result of PDCCPSA with existence algorithm MADSEC, EFTCP, PDMECCA in terms of network lifetime and total remaining energy for 100 nodes. In figure 7, plot between number of rounds and alive nodes demonstrate that PDCCPSA increase the network lifetime by $242 \%$ compared to MADSEC, 866\% compared to EFTCP and 58.5\% compared to PDMECCA. In Figure 8, plot between number of rounds and total remaining energy demonstrate that proposed algorithm PDCCPSA hold total remaining energy of network approximate 13.55 joule which is higher 13.55 joule and 13.55 joule as compared to EFTCP, MADSEC and PDMECCA respectively in $2079^{\text {th }}$ round. If network life time increases so we can say that coverage also preserve because network life time directly proportional to the coverage. In figure 9, PDCCPSA compare with PDMECCA algorithm in terms of coverage. According to the figure 9 PDCCPSA provide the almost full coverage till 2689 rounds and PDMECCA provide the complete coverage till 1736 rounds.

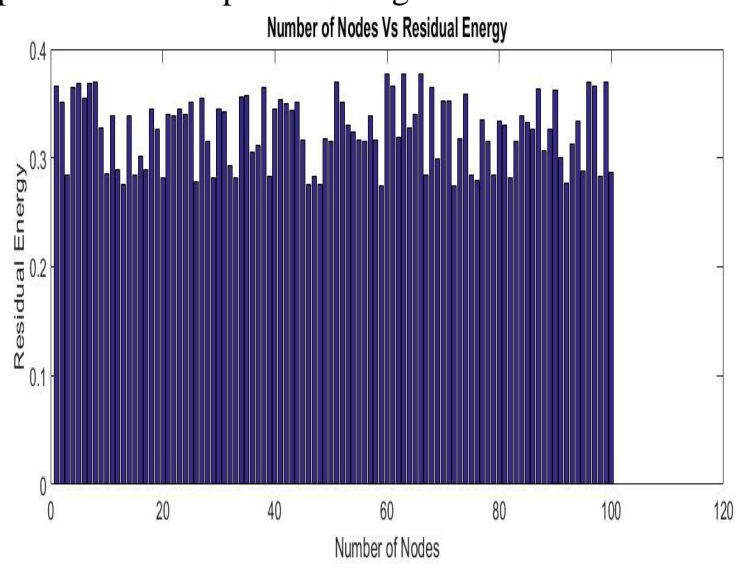

Figure 3: Remaining Energy level per node after 1000 rounds

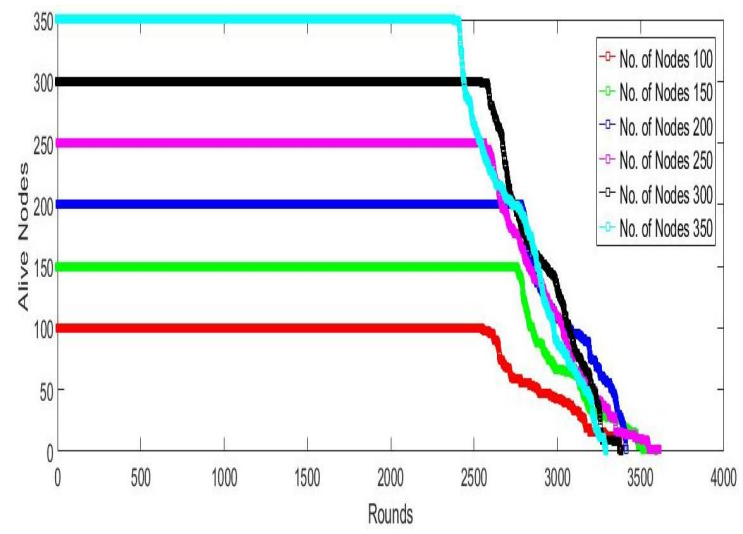

Figure 4: Alive nodes per rounds for 100, 150, 200, 250, 300, 350 nodes

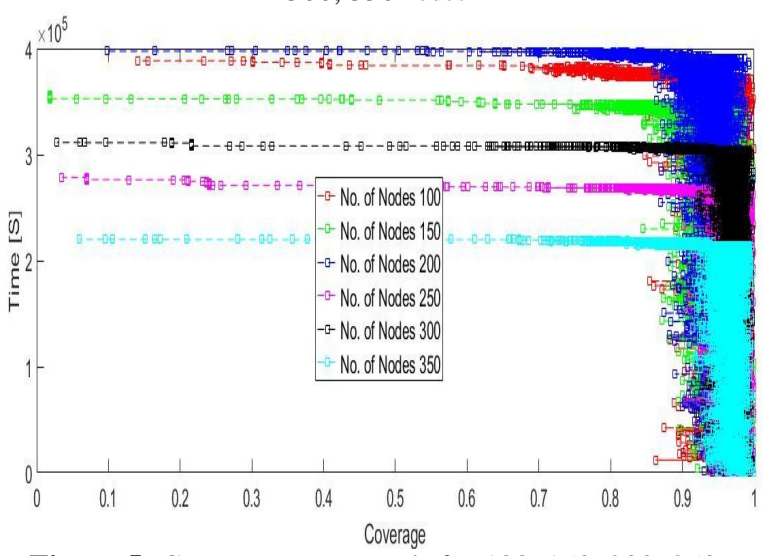

Figure 5: Coverage per Rounds for 100, 150, 200, 250, 300, 350 nodes

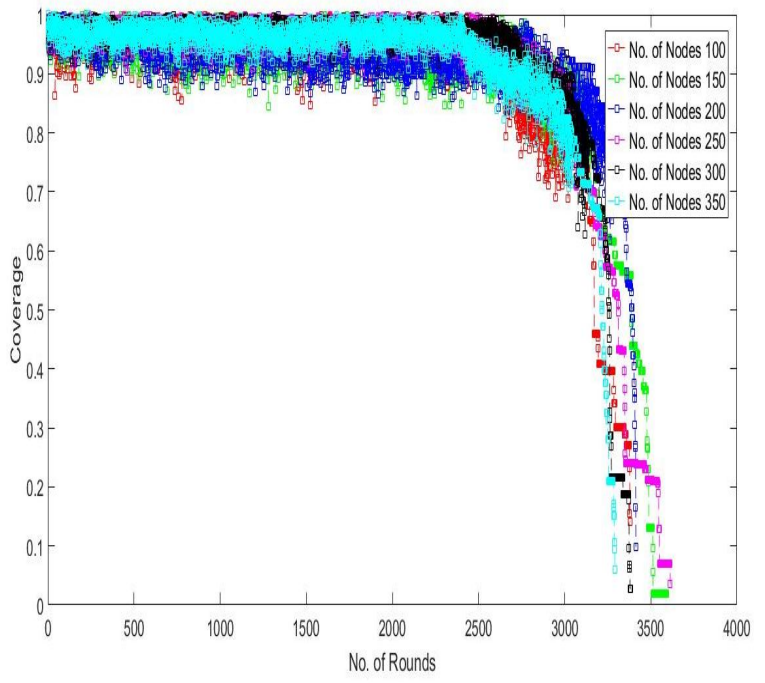

Figure 6: Coverage Per time for 100, 150, 200, 250, 300, 350 nodes 


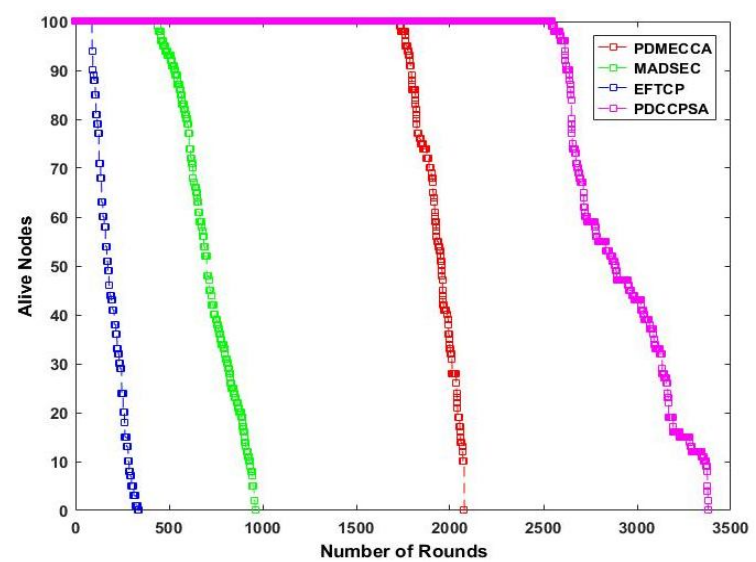

Figure 7: Comparison of PDCCPSA with other algorithms in terms of alive nodes and number of rounds

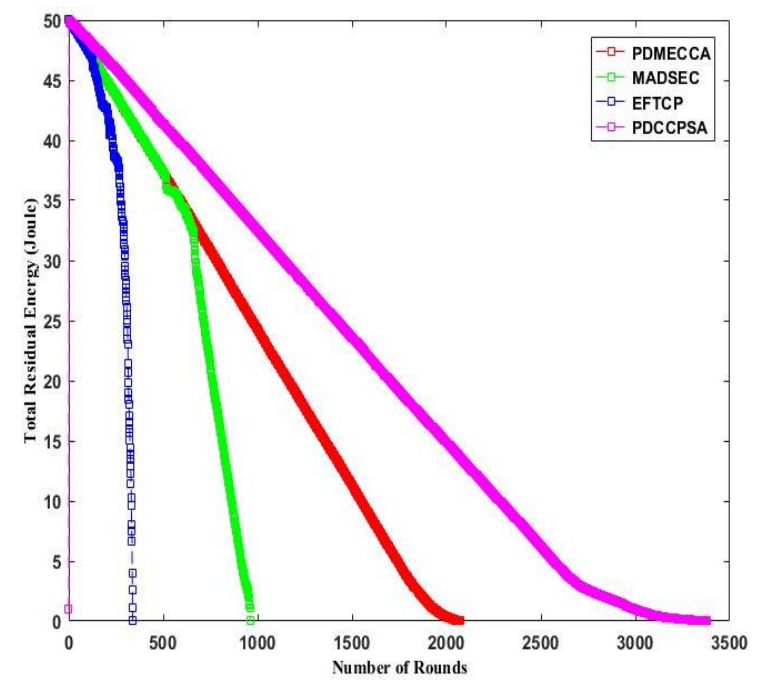

Figure 8: Comparison of PDCCPSA with other algorithms in terms of number of rounds and total residual energy

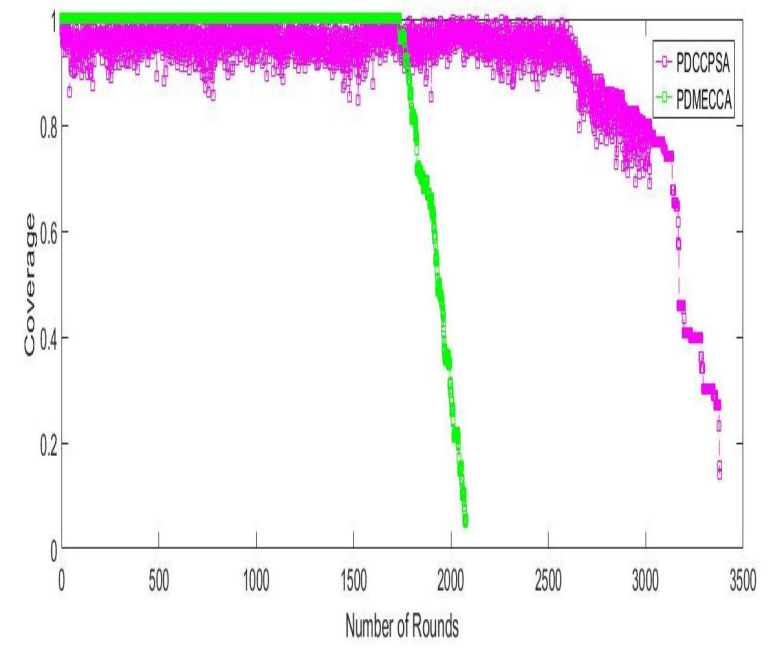

Figure 9: Comparison of PDCCPSA with PDMECCA in terms of Coverage

\section{CONCLUSION}

This paper proposed a scheduling algorithm PDCCPSA. This paper conclude that PDCCPSA rises the lifetime of network, offers continuously coverage and connectivity, declines the energy consumption, declines data transmission distance among nodes, fairly allocate burden in all nodes and decrease the number of hops between nodes and sink.

\section{REFERENCES}

[1] R.Tamil Kodi, L.Venkateshwara Kiran, V.L.Sailaja and M.V.Subba Rao, Performance analysis of WRP with mobile sink based on data collection to base station in a WSN, IJATCSE, Volume 7, No.6, PP 82-86, Nov-Dec 2018. https://doi.org/10.30534/ijatcse/2018/13762018 [2] S.V.R.K.Rao, M.Saritha Devi, A.R.Kishore and Praveen Kumar, Wireless sensor Network based Industrial Automation using Internet of Things (IoT), IJATCSE, Volume 7, No.6, PP , Nov-Dec 2018.

https://doi.org/10.30534/ijatcse/2018/01762018 [3] Yi Sun, Yagang Zhang, New Developments of Characteristic Analysis in Wireless Sensor Networks, IETE Journal of Research, Sep 2015. https://doi.org/10.1080/03772063.2015.1084897

[4] Mohammad Ahmadinia, Mohammad Reza Meybodi, Mahdi Esnaashari \& Hamid AlinejadRokny, Energy-efficient and Multi-stage Clustering Algorithm in Wireless Sensor Networks Using Cellular Learning Automata, IETE Journal of Research, Volume 59, Issue 6, pp. 774-782, 2013.

https://doi.org/10.4103/0377-2063.126958

[5]I. F. Akyildiz , W. Su , Y. Sankarasubramaniam and E. Cayirci, A survey on sensor networks, IEEE Communications Magazine, Volume 40 , Issue 8, pp. $102-114,2002$.

https://doi.org/10.1109/MCOM.2002.1024422

[6] Mohammed Saeed Al-kahtani, Cluster-based Coverage-aware Node Scheduling Scheme for Mobile Wireless Sensor Network, IEEE Eleventh International Symposium on Autonomous Decentralized Systems (ISADS), Maxico, 6-8 March 2013.

https://doi.org/10.1109/ISADS.2013.6513443

[7] Zhou Xin-lian, Xu Jian-bo, The Research of Inner-cluster Nodes Scheduling Algorithm in mWSN, International Forum on Information Technology and Applications, IEEE Computer Society, 2010.

https://doi.org/10.1109/IFITA.2010.229

[8] Kai Li, Kien A. Hua, Mobility-assisted Distributed Sensor Clustering for Energy-efficient Wireless Sensor Networks, IEEE Global Communications Conference (GLOBECOM), pp. 316 - 321, 2013. 
[9] XiongQi Zheng, Yong Feng, Jie Yang and ZhiQiang Lu, Energy Efficient and Fault Tolerant Routing Protocol for Mobile Wireless Sensor Networks, International Conference on Information and Communications Technologies, pp. 1-5, 15-17 May 2014.

https://doi.org/10.1049/cp.2014.0627

[10] Jitendra Singh Verma, Sanjeev Sharma, PROMETHEE based Distributed Multihead Energy and Coverage Preserving Clustering Algorithm for Mobile Sensor Nodes, National Academy Science Letters, Springer, pp. 1-5, may. 2019.

[11] Stanislava Soro, Wendi B. Heinzelman, Cluster head election techniques for coverage preservation in wireless sensor networks, Ad Hoc Networks, Volume 7, Issue 5, PP. 955-972, 2009.

https://doi.org/10.1016/j.adhoc.2008.08.006

[12] Shiow-Fen Hwang, Yi-Yu Su, Yi-Yo Lin and Chi-Ren Dow, A Cluster-Based CoveragePreserved Node Scheduling Scheme in Wireless Sensor Networks, Third annual international conference on mobile and ubiquitous systems: Networkingand services, 2006. https://doi.org/10.1109/MOBIQ.2006.340443

[13] Brans, J. P. and Vincke, P. H., A preference ranking organization method: the PROMETHEE method for multiple criteria decision making, Management Science, 31, PP. 647-656, 1985.

https://doi.org/10.1287/mnsc.31.6.647 